\title{
The Marine Single Assignment Nonstrict Hub Location Problem: Formulations and Experimental Examples
}

\author{
Shang-Hsing Hsieh \\ Associate Professor, Department of Transportation Technology and Management, National Chiao Tung University, \\ Hsinchu, Taiwan, R.O.C, shhsieh@cc.nctu.edu.tw \\ Hsien-Lun Wong \\ Ph.D. Candidate, Department of Transportation Technology and Management, National Chiao Tung University, \\ Hsinchu, Taiwan, R.O.C.
}

Follow this and additional works at: https://jmstt.ntou.edu.tw/journal

Part of the Civil and Environmental Engineering Commons

\section{Recommended Citation}

Hsieh, Shang-Hsing and Wong, Hsien-Lun (2004) "The Marine Single Assignment Nonstrict Hub Location Problem: Formulations and Experimental Examples," Journal of Marine Science and Technology. Vol. 12: Iss. 4, Article 14. DOI: $10.51400 / 2709-6998.2255$

Available at: https://jmstt.ntou.edu.tw/journal/vol12/iss4/14

This Research Article is brought to you for free and open access by Journal of Marine Science and Technology. It has been accepted for inclusion in Journal of Marine Science and Technology by an authorized editor of Journal of Marine Science and Technology. 
The Marine Single Assignment Nonstrict Hub Location Problem: Formulations and Experimental Examples

\section{Acknowledgements}

The authors are very grateful to the editor, Professor Chorng-Liang Pan, and two anonymous referees for their astute observations and helpful comments. This project was supported by the National Science Council of Taiwan with grant 90-2416-H-009-004. 


\title{
THE MARINE SINGLE ASSIGNMENT NONSTRICT HUB LOCATION PROBLEM: FORMULATIONS AND EXPERIMENTAL EXAMPLES
}

\author{
Shang-Hsing Hsieh* and Hsien-Lun Wong**
}

Key words: hub location, integer programming, heuristics, quadratic assignment.

\begin{abstract}
Marine hub-and-spoke networks have been applied to routing containerships for over two decades, but few papers have devoted their attention to these networks. The marine network problems are known as single assignment nonstrict hub location problems (SNHLPs), which deal with the optimal location of hubs and allocation of spokes to hubs in a network, allowing direct routes between some spokes. In this paper we present a satisfactory approach for solving SHNLPs. The quadratic integer profit programming consists of two-stage computational algorithms: a hub location model and a spoke allocation model. We apply a heuristic scheme based on the shortest distance rule and an experimental case based on the Trans-Pacific Routes is presented to illustrate the model's formulation and solution methods. The results indicate that the model is a concave function, exploiting the economies of scale for total profit with respect to the number of hubs. The spoke allocation may change an optimal choice of hub locations.
\end{abstract}

\section{INTRODUCTION}

A number of studies have recently been done on the network design problem for hub-and-spoke patterns. Although marine hub-and-spoke networks have been applied to routing containerships for over two decades, few papers have so far devoted their attention to these networks. Some papers formulated mathematical programming models for routing containerships, but these models neglect the characteristics of containerships' routes. Different systems require different models to adequately portray scenario patterns based upon their characteristic features (O'Kelly, 1998; Bryan and O'Kelly, 1999). The aim of this paper is to develop a

Paper Submitted 08/04/04, Accepted 09/21/04. Author for Correspondence: Shang-Hsing Hsieh. E-mail: shhsieh@cc.nctu.edu.tw.

*Associate Professor, Department of Transportation Technology and Management, National Chiao Tung University, Hsinchu, Taiwan, R.O.C. **Ph.D. Candidate, Department of Transportation Technology and Management, National Chiao Tung University, Hsinchu, Taiwan, R.O.C. more adequate model for capturing the particular characteristics of marine networks, while maximizing the total transportation profit of the network.

Transportation networks, in which traffic moves from its origin node to its destination node, are often configured as hub-and-spoke systems. In such systems, hubs are special nodes that serve as consolidation and switching points that connect many origins and destinations. The concept of these interacting hubs arises frequently in many applications, such as air passenger travel, telecommunication network, postal delivery systems, and containerships. The major incentive for employing a hub-and-spoke systems is that hubs enjoy economies of scale achieved by larger consolidating traffic into smaller number of hub-to-hub links, thus generating lower unit transportation cost on those links. Hub-and-spoke networks usually consist of at least a two-level system: hub level and spoke level. The hubto-hub portion is usually discounted by a factor $\alpha(0<$ $\alpha \leq 1$ ) to account for the concept of hubbing economies.

The hub location problems (HLPs) are to determine an optimal number and location of hubs, and allocation of spokes (non-hubs) to these hubs in a network such that, typically, the total transportation cost is minimized. Since O'Kelly (1986a, 1986b, 1987) first proposed a quadratic integer programming and two heuristic algorithms for solving the HLPs, an increasing number of studies have been done on this prototype of the problems, such as Campbell (1994) and O'Kelly and Miller (1994). Campbell (1994) presented the HLPs into four different basic categories: the p-hub median problem, the uncapacitated hub location problem, $p$ hub center problems, and hub covering problems. Most of work on HLPs has focused on the former two problems. If the number of hubs is not given in a network, the $p$ hub median problem is usually the HLP. In uncapacitated HLPs, there is a fixed cost for establishing a hub, but no constraint on the number of hubs (Campbell, 1994; Klincewicz, 1996; Ebery et al., 2000). Different assumptions may result in different problem structures and network patterns. For example, a single assignment 
is structured so that each spoke is assigned to only one hub (O'Kelly, 1987, 1992; Klincewicz, 1991, 1992; Campbell, 1994, 1996; Skorin-Kapov and Skorin-Kapov, 1994; Skorin-Kapov et al., 1996; Aykin, 1990, 1995; Ernst and Krishnamoorthy, 1996; Kara, et al. 2003). A multiple assignment allows spokes to interact with more than one hub (Campbell, 1994; O'Kelly and Lao, 1991; Klincewicz, 1996; Skorin-Kapov et al., 1996; Krishnamoorthy et al., 1998, 2000). Occasionally, there is also a fixed cost to establish a hub (O'Kelly, 1992; Campbell, 1994; Aykin, 1995; O'Kelly et al., 1996; Sohn and Park, 1998). In some cases, it is possible to allow direct routes between some spokes, resulting in a problem called "Nonstrict Hubbing Policy" (Aykin, 1994, 1995).

Despite its widespread use, designing efficient hub-and-spoke systems remains a challenging task. A primary difficulty lies in model formulations and solution algorithms for the characteristic of a particular system. As a result of the computational needs in solving HLPs, previous studies primarily focused on heuristic algorithms rather than exact solutions for models. O'Kelly (1987) was first to develop two enumeration-based heuristics using distance rule for solving the single assignment $p$-hub median problem, in which every spoke is allocated to exactly one hub and all hub linkages are fully interconnected (i.e., a pure hub-and-spoke network). Klincewicz (1991) proposed two sets of heuristics for larger problems based on a multi-criteria distance and flow rule rather than on distance alone. Klincewicz's exchange heuristics first determine the hub locations, and then assignment of spokes to hubs, with changes the solution made by the assignment of hubs to spokes. The other clustering heuristics divide the nodes into several groups and assign a hub for each group. In later work, Klincewicz (1992) considered tabu search and greedy search procedures to explore solutions beyond local optima. SkorinKapov and Skorin-Kapov (1994) developed other tabu search heuristic, assigning equal importance to the location and allocation portions of the problem. Aykin (1994) was first to consider the Langrangian relaxation for the $p$-hub median problem with hub capacity. Aykin (1995) provided a branch-and-bound algorithm and a simulated annealing based on greedy interchange heuristic for investigating the effects of strict and nonstrict on the HLPs. In strict hubbing, all traffic must ship via a set of hubs; nonstrict hubbing allows some direct trips between some spokes. Klincewicz (1996) proposed a dual ascent procedure for a sequence of uncapacitated HLPs. O'Kelly et al. (1995) presented algorithm to determine two lower bounds on the optimal solution. Skorin-Kapov et al. (1996) developed effective mixed integer formulations with tight linear programming re- laxations for the HLPs. Campbell (1996) was first one to formulate a greedy exchange heuristic to solve uncapacitated, multiple assignment HLPs. The MAXFLO heuristic assigns spoke to hub by maximum flow rule, whereas the ALLFLO's purpose is to minimize the total network cost. By modifying Campbell's model (Campbell, 1996), Skorin-Kapov et al. (1996) were first to propose mixed integer formulations for finding exact solutions for the single and multiple assignment problems. Ernst and Krishnamoorthy (1996) also developed a two-stage approach to produce exact solutions. Sohn and Park (1998) provided a reduced size formulation model for uncapacitated single and multiple p-hub location problems. Ernst and presented exact and heuristic algorithms for the uncapacitated multiple assignment HLPs, while Ebery et al. (2000) presented mixed integer formulations using branchand-bound algorithm, based on the shortest path rule, for the capacitated multiple assignment problem. Boland et al. (2004) considered pre-processing procedures and tightening constraints with existing mixed integer linear programming model for multiple assignment problem.

Recently, Kara and Tansel (2000) and Pamuk and Sepil (2001) studied the p-hub center problem, and Kara and Tansel (2003) have also investigated the hub covering problem.

Marine containership routes are hub-and-spoke structures, in which containerships carry cargo from their origin ports, through hub ports in the network, to their destination ports. In this paper, the problem is the HLP as previously studied, but for different applications. There are three fundamental differences: (1) In past HLPs, hubs are fully interconnected, whereas in marine problems, hubs are not fully networks; rather they are more like shuttle patterns. The hub connections are sequential and in the same directional order (Hsieh and Chang, 2001). (2) In past HLPs, traffic is shipped via set of hubs, and each spoke connects to a hub. In marine problems, however, some spokes may bypass others to connect to a hub (see Gilman, 1981; Pearson and Fossey, 1983). In such an allocation, marine network problems can be classified as nonstrict hubbing policy, as defined by Aykin (1995). (3) In past HLPs, the interhub cost counts by only cost with hub link. In marine problems, the interhub cost has to accumulate all cost on each interhub link, reflecting the hub level structure. Consequently, the definition of our problem having such features to be discussed in this paper is referred to as single assignment, nonstrict hub location problems (SNHLPs). These problems have not yet been studied in previous literature.

Due to the increased traffic at hub ports, marine liner operators can benefit from the scale economies of 
ship capacity utilized at hub ports (Chadwin et al., 1990). In order to take full advantage of this, however, it is critical for liner operators to solve marine SNHLPs. Yet these problems have received limited attention in the literature. Ronen (1993) reviewed literature from the last decade regarding routing and scheduling problems and identified only a few that pertained to routing containerships. Rana and Vickson (1998, 1991) proposed a mixed integer nonlinear programming combined with decomposition to solve the optimal routing problem. Jaramillo and Perakis (1991), Cho and Perakis (1996), and Powell and Perakis (1997) developed linear programming to describe the routing containerships and deployment scenario. Christiansen and Nygreen (1998) presented an optimal solution based on branch-andbound search with inventory constraints for ship routing problems.

Fagerholt (1999) identified optimal ship types, the number for each type, and coherent routes for the liner shipping problem. Lu (2002) proposed a branch-andbound algorithm with cycle time and vessel constraints for an optimal ship routing. Chu et al. (2003) proposed a mixed integer model to determine an optimal sequence of port calls and container flow between demand ports with cycle time constraints. Azaron and Kianfar (2003) applied a stochastic dynamic programming based on semi-Markov decision processes and network flow theory to find the dynamic shortest path for ship routing problem. These studies neglected the reality of marine routing problem, resulting in models that were complicated and possibly generated unrealistic solutions to marine SNHLPs. Recently, Mourao et al. (2002) developed an integer programming model to solve ship fleet assignment with defined voyages based on hub-andspoke networks. Hsieh and Chang (2001) proposed an integer linear programming, which modified O'Kelly's model (O'Kelly, 1987), to solve marine SNHLPs. In later work, Hsieh and Wong (2003) proposed a quadratic integer cost minimization model with heuristic algorithms based on distance rule for the same problem. In this paper we propose an extensive approach for marine SNHLPs. The model is larger and more complicated than the cost minimization model of Hsieh and Wong (2003) because: (1) the cost minimization model considered only transportation cost, whereas this model considers simultaneously the tradeoffs between revenue and related costs (e.g., fixed cost, sailing cost, port cost, operational cost, and bunker cost). (2) In cost minimization model, no ship assignment is included. In this model, however, different ship sizes are deployed to the two-level system, introducing additional sets of constraints (e.g., load capacity, cargo carried when vessel outgoing and returning, planning horizon). (3) In this model, the frequency of service and the number of vessels are viewed as decision variables. With these considerations, the model can more adequately represent the reality of the existing problems. To the best of our knowledge, this is the first work to provide a means to explicitly address tradeoffs between revenue and cost on the HLPs in the literature; even we can imagine many similar applications.

Our approaches are tested on a data set from TransPacific Routes. Parts of traffic flow are estimated from various sources because real data are not generally available.

The next section presents the problem formulation for marine SNHLPs and the quadratic profit model. Section Three provides the solution processes for both the hub location model and the spoke allocation model. Section Four implements an experimental case based on the Trans-Pacific Routes data to illustrate the model's formulation and the solution methods. Finally, we discuss our conclusions and propose directions for future research.

\section{MODEL FORMULATION}

The model seeks to establish the basis for marine network design by determining the optimal location of hubs and allocation of feeder ports to these hubs, such that the annual total profit is maximized. The containership service level consists of many elements, such as service safety, pick-up and delivery time, and available load capacity, but to make it quantitative, some variables in this formulation are available capacity, traffic flow, traffic rate, ship size, sailing speed, voyage distance, bunker price, and sailing frequency.

In marine hub-and-spoke networks, traffic flow from origin node $i n^{o}$ to destination node $j n^{d}$ usually has three segments associated with it, denoted as consolidation, transshipment, and distribution. Consolidation represents the traffic from origin node ino to hub $i$ (spoke level), transshipment is traffic movement between hub $i$ to hub $j$ (hub level), and distribution reflects traffic from hub $j$ to destination node $j n^{d}$ (spoke level). Each of these yields tradeoffs between revenue and cost. For ship deployment problems, larger containerships are usually assigned to transshipment segments due to the economies of scale in larger consolidating traffic, whereas smaller ones are assigned to consolidation and distribution segments. In reality, there would be usually less than twenty ports serving a network in both directions (Rana and Vickon, 1991). The data used for examining the quadratic integer model contains 12 ports. Most existing formulations of HLPs are based on an $n \times n$ symmetric data matrix, for example, traffic flow $F_{j i}=F_{i j}$. While this is not a restriction in our study, we show how this property can be exploited if it 
exists.

A twofold computational algorithm is designed to determine the network solution. The hub location model first chooses the number of hubs for transshipment segments, under single assignment constraint, and then the spoke allocation model assigns spokes to hubs for consolidation and delivery segments, with nonstrict hubbing policy. Finally, the model compares all possible solutions of the two models' combinations and determines the optimal solution to marine SNHLPs, while maximizing the total profit [i.e., $\operatorname{Max}(Z 1+Z 2)]$.

\section{The hub location model}

(1) There are several postulates in this stage of formulation:

- The traffic flow between ports is given.

- The sailing cost of each voyage leg between ports is given.

- The expenses for mother vessel wharfing and cargo loading are given.

- The load capacity of a mother vessel is 5,000 TEU.

- The daily fixed cost of a mother vessel is given.

- The sequence for mother vessel shuttling between hub ports is given.

\section{(2) Decision parameters}

$P_{i j}=$ Freight rate per TEU from hub port $i$ to hub port $j$,

$F_{i j}=$ Traffic flow from hub port $i$ to hub port $j$,

$S_{i j}^{m}=$ Sailing cost of a mother vessel on voyage leg $(i, j)$,

$O_{i}^{m}=$ Port cost for a mother vessel at hub port $i$,

$L_{i}^{m}=$ Number of TEUs carried on a mother vessel before arriving hub port $i$,

$W_{i}^{m}=$ Wharfing fee of a mother vessel at hub port $i$,

$U_{i}=$ Loading cost per TEU at hub port $i$,

$D^{m}=$ Daily sailing cost of a mother vessel,

$C^{m}=$ Daily fixed cost of a mother vessel,

$Q^{m}=$ Load capacity of a mother vessel,

$N^{m}=$ Number of mother vessels deployed at the hub level,

$R^{m}=$ Frequency of service for a mother vessel within one-year planning horizon.

(3) Mathematical models

Objective function

$\operatorname{Max}$

$$
\begin{aligned}
Z 1 & =\left(\sum_{i=1}^{n} \sum_{j=1}^{n} P_{i j} F_{i j} z_{i j}-\sum_{i=1}^{n} \sum_{j=1}^{n} S_{i j}^{m} y_{i j}-\sum_{i=1}^{n} O_{i}^{m} x_{i}\right) \\
& \times N^{m} \times R^{m}-365 \times N^{m} \times C^{m}
\end{aligned}
$$

Subject to Outgoing voyage

$$
L_{i, o}^{m}=\sum_{p=1}^{i} \sum_{j=i+1}^{n} F_{p j} z_{p j} x_{i} \leq Q^{m} \quad i=1,2, \ldots, n .
$$

Returning voyage

$$
L_{i, r}^{m}=\sum_{p=i}^{n} \sum_{j=1}^{i-1} F_{p j} z_{p j} x_{i} \leq Q^{m} \quad i=1,2, \ldots, n .
$$

where the variables are defined as following: $x_{i}=1$ if a mother vessel berths at hub port $i$, and $x_{i}=0$ if otherwise. If hub port $i$ is directly connected to hub port $j$, then $y_{i j}$ $=1$, and $y_{i j}=0$ if otherwise. This guarantees that every port is assigned to only one hub port. If the node is a hub port, then it is assigned to itself. Thus, the problem is a single assignment. If a mother vessel berths at hub port $i$ and $j$, then $z_{i j}=1$, and $z_{i j}=0$ if otherwise.

The objective function (1) maximizes the total profit for mother vessels on the hub level. Constraints (2) and (3) ensure that the cargo carried on a mother vessel leaving or arriving at hub port i does not exceed the load capacity $Q^{m}$. Two cost items in the model (1) are formulated by:

$$
\begin{aligned}
& S_{i j}^{m}=D^{m}\left[d_{i j} \div\left(v^{m} \times 24\right)\right] \\
& i=1,2, \ldots, n, j=1,2, \ldots, n .
\end{aligned}
$$

and

$$
\begin{aligned}
& O_{i}^{m}=2 W_{i}^{m}+U_{i}\left(\sum_{p=1}^{n} F_{p i} z_{p i}+\sum_{p=1}^{n} F_{i p} z_{i p}\right) \\
& i=1,2, \ldots, n .
\end{aligned}
$$

frequency of a mother vessel within one-year planning horizon in the model (1) is given by:

$$
R^{m}=365 \div\left(\sum_{i=1}^{n} \sum_{j=1}^{n} T_{i j}^{m s} y_{i j}+\sum_{i=1}^{n} T_{i}^{m b} x_{i}\right)
$$

where $d_{i j}$ is the distance between hub port $i$ and hub port $j$ in nautical miles, $v^{m}$ is the speed of a mother vessel in knots, $T_{i j}^{m s}$ is the sailing time of a mother vessel on voyage leg $(i, j)$, and $T_{i}^{m b}$ is the berthing time of a mother vessel at hub port $i$.

\section{The spoke allocation model}

(1) Postulates of this model are as follows:

- The traffic flow of every port is given.

- The traffic rate per TEU is given.

- The sailing cost of each leg for a feeder vessel is given. 
- The wharfing and loading cost of each port is given.

- The load capacity of a feeder vessel is 1,000 TEU.

\section{(2) Decision parameters}

$P_{(i n) j}=$ Freight rate per TEU from feeder port in to hub port $j$,

$P_{j(i n)}=$ Freight rate per TEU from hub port $j$ to feeder port in,

$P_{\left(i n^{o}\right)\left(j n^{d}\right)}=$ Freight rate per TEU from feeder port $i n^{o}$ to feeder port $j n^{d}$,

$F_{(i n) j}=$ Traffic flow from feeder port in to hub port $j$,

$F_{j(i n)}=$ Traffic flow from hub port $j$ to feeder port in,

$F_{(i n)(j n)}=$ Traffic flow from feeder port in to feeder port jn,

$\left.S_{\left({ }_{i n}{ }^{o}\right)(j n}^{f}{ }^{d}\right)=$ Sailing cost of a feeder vessel on voyage leg $\left(i n^{o}, j n^{d}\right)$,

$O_{i n}^{f}=$ Port cost for a feeder vessel at feeder port in,

$O_{i}^{f}=$ Port cost for a feeder vessel at hub port $i$,

$U_{i}^{f}=$ Loading cost of a feeder vessel at hub port $i$,

$L_{i n}^{f a}=$ Number of TEUs carried on a feeder vessel arriving feeder port $i n$,

$L_{i}^{f l}=$ Number of TEUs carried on a feeder vessel leaving hub port $i$,

$W_{i n}^{f}=$ Wharfing fee of a feeder vessel at feeder port in,

$U_{i n}=$ Loading cost per TEU at feeder port in,

$D^{f}=$ Daily fixed cost of a feeder vessel,

$C^{f}=$ Daily sailing cost of a feeder vessel,

$Q^{f}=$ Load capacity of a feeder vessel,

$N_{i}^{f}=$ Number of feeder vessels deployed to spoke level,

$R_{i}^{f}=$ Frequency of service for a feeder vessel within one-year planning horizon.

where $i$ is the location of hub ports, and in is the $n$-th feeder port assigned to hub port $i$ (e.g., $i n=11,21,22$, $32, \ldots, \mathrm{nm})$. The two-digit number describes the assignment order of feeder ports to hub ports. For example, when in $=21$, this port is the first feeder port assigned to the second hub port in a network. When in $=22$, this port is the second feeder port assigned to the second hub port, and so on.

(3) Mathematical models (Hsieh et al., 2002)

Objective function

$$
\begin{aligned}
& \text { Max } \\
& \begin{aligned}
Z & \left(\sum_{i=1}^{n} \sum_{n=1}^{m_{i}} \sum_{j=1}^{n} P_{(i n) j} F_{(i n) j} x_{i j} z_{i j}\right. \\
& +\sum_{i=1}^{n} \sum_{j=1}^{n} \sum_{n=1}^{m_{j}} P_{i(j n)} F_{i(j n)} x_{j n} z_{i j}
\end{aligned}
\end{aligned}
$$

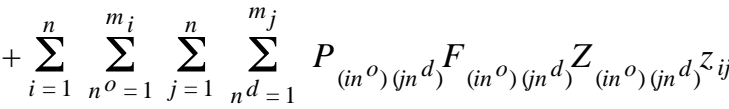

$$
\begin{aligned}
& \left.-\sum_{i=1}^{n} L_{i}^{f} x_{i}\right) \times N^{m} \times R^{m}-\sum_{i=1}^{n} \sum_{n_{o}=0}^{m_{i}} \sum_{n_{d}=1}^{m_{i}+1} N_{i}^{f}
\end{aligned}
$$

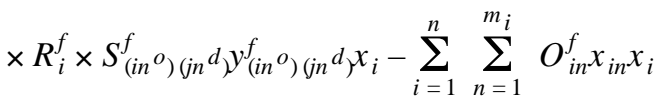

$$
\begin{aligned}
& -365 \times C^{f} \times \sum_{i=1}^{n} N_{i}^{f} x_{i}
\end{aligned}
$$

Subject to

Outgoing voyage

$$
\begin{aligned}
L_{i, o}^{m} & =\sum_{p=1}^{i} \sum_{j=j+1}^{n} F_{p j} z_{p j}+\sum_{p=1}^{i} \sum_{j=j+1}^{n} \sum_{n^{d}=1}^{m_{j}} F_{p(j n} d^{d} x_{(j n} d^{d} z_{p j} \\
& +\sum_{p=1}^{i} \sum_{n^{o}=1}^{m_{p}} \sum_{j=j+1}^{n} F_{\left(p n^{o}\right) j} x_{\left(p n^{o}\right)} z_{p j} \\
& \left.+\sum_{p=1}^{i} \sum_{n^{o}=1}^{m_{p}} \sum_{j=j+1}^{n} \sum_{n^{d}=1}^{m_{j}} F_{\left(p^{o}\right)(j n} d^{d} z_{\left(p n^{o}\right)(j n} d\right)_{p j} \\
& \leq Q^{m} \quad i=1,2, \ldots, n .
\end{aligned}
$$

Returning voyage

$$
\begin{aligned}
& L_{i, r}^{m}=\sum_{p=1}^{i} \sum_{j=i}^{i-1} F_{p j} z_{p j}+\sum_{p=1}^{i} \sum_{j=1}^{i-1} \sum_{n=1}^{m_{j}} F_{p(j n} d x_{(j n}{ }^{d} z_{p j} \\
& +\sum_{p=1}^{i} \sum_{n^{o}=1}^{m p} \sum_{j=1}^{j-1} F_{(p n o) j} x_{p n} o z_{p j} \\
& \left.+\sum_{p=1}^{i} \sum_{n^{o}=1}^{m_{p}} \sum_{j=j+1}^{n} \sum_{n^{d}=1}^{m_{j}} F_{\left(p n^{o}\right)(j n}{ }^{d} z_{\left(p n^{o}\right)(j n}{ }^{d}\right)_{p j} \\
& \leq Q^{m} \quad i=1,2, \ldots, n . \\
& L_{i n}^{f a}=\sum_{p=1}^{i} \sum_{n}^{m_{i}} F_{p(i n} d x_{i n} d z_{p i} \\
& +\sum_{p=1}^{i} \sum_{n^{o}=1}^{m_{p}} \sum_{n^{d}=n+1}^{m_{i}} F_{\left(p n^{o}\right)(i n} z_{\left(p n^{o}\right)(i n} d z_{p i} \\
& \left.+\sum_{n}^{n} \sum_{i p=i}^{n} F_{(i n}^{o}\right) p x_{i n} o z_{i p} \\
& \left.\left.+\sum_{n=1}^{n} \sum_{p=i+1}^{n} \sum_{n^{d}=1}^{m_{p}} F_{(i n}{ }^{o}\right)(p n d) z_{(i n}{ }^{o}\right)(p n d) z_{i p} \\
& i=1,2, \ldots, n, j=1,2, \ldots, m_{j} \text {. } \\
& L_{i}^{f l}=\sum_{p=1}^{i} \sum_{n}^{m_{i}} F_{p(i n} d x_{i n} d z_{p i}
\end{aligned}
$$




$$
\begin{aligned}
& \left.\left.+\sum_{p=1}^{i} \sum_{n^{o}=1}^{m_{p}} \sum_{n^{d}=1}^{m_{i}} F_{\left(p n^{o}\right)(i n}{ }^{d}\right)_{\left(p n^{o}\right)(i n} d\right)_{p i} \leq Q^{f} \\
& i=1,2, \ldots, n .
\end{aligned}
$$

where $x_{i n}=1$ if a feeder vessel berths at feeder port in, and $x_{i n}=0$ if otherwise. If feeder ports $i n$ and $j n$ are connected directly, then $y_{(i n)(j n)}=1$; if a feeder vessel berths in both port in and $j n$, then $z_{(i n)(j n)}=1$. Both decision variables of $y_{(i n)(j n)}$ and $z_{(i n)(j n)}$ reflect the nonstrict hubbing policy.

The objective function (7) indicates the maximum profit available for a feeder vessel on the spoke level. Constraints (8) and (9) ensure that the load capacity of a mother vessel leaving or arriving at a hub port is less than $Q^{m}$. Constraint (10) is the load capacity limit of a feeder vessel at each of its feeder ports. Constraint (11) indicates that the amount of cargo carried on a feeder vessel should be less than $Q^{f}$ when departing from a hub port for feeder ports. The port cost of feeder vessels at hub port $\left(O_{i}^{f}\right)$ is related to the number of feeder vessels and their number of port calls at feeder ports within a one-year planning horizon. In a hub and spoke network, the increased loading costs at the hub port are a result of the additional loading activities of feeder vessels. Some cost parameters in the model (7) are formulated as following:

$$
\begin{aligned}
& O_{i n}^{f}=N^{f} \times R^{f} \times W_{i n}^{f}+U_{i n}\left(\sum_{p=1}^{n} F_{p(i n)} x_{i n} z_{p i}\right. \\
& +\sum_{p=1}^{n} \sum_{n^{\prime}=1}^{m_{p}} F_{\left(p n^{\prime}\right)(i n)^{2}} z_{\left(p n^{\prime}\right)(i n)^{2}} z_{p i}+\sum_{p=1}^{n} F_{(i n) p} x_{i n} z_{i p} \\
& \left.+\sum_{p=1}^{n} \sum_{n^{\prime}=1}^{m_{p}} F_{(i n)\left(p n^{\prime}\right)^{\prime}} z_{(i n)\left(p n^{\prime}\right)^{\prime}} z_{i p}\right) \times N^{m} \times R^{m} \\
& i=1,2, \ldots, n \text {. } \\
& O_{i}^{f}=N^{f} \times R^{f} \times W_{i}^{f}+U_{i}\left(\sum_{p=1}^{n} \sum_{n=1}^{m_{i}} F_{p(i n)} x_{i n} z_{p i}\right. \\
& +\sum_{p=1}^{n} \sum_{n^{o}=1}^{m_{p}} \sum_{p=1}^{m_{i}} F_{\left(p n^{o}\right)(i n)^{Z}}{ }_{\left(p n^{o}\right)(i n)^{z} p i} \\
& +\sum_{n=1}^{m_{i}} \sum_{p=1}^{n} F_{(i n) p} x_{i n} z_{i p} \\
& \left.\left.+\sum_{n=1}^{m_{i}} \sum_{p=1}^{n} \sum_{n}^{m^{p}} F_{(i n)(p n} d\right)_{(i n)(p n} d\right)^{z_{i p}} \\
& \left.\left.-\sum_{n^{o}=1}^{m_{j}} \sum_{n^{d}=1}^{m_{i}} F_{\left.\left({ }^{\circ}{ }^{o}\right)\left(i n^{d}\right)_{(i n}{ }^{o}\right)(i n} d\right) x_{i}\right) \times N^{m} \times R^{m} \\
& i=1,2, \ldots, n \text {. }
\end{aligned}
$$

$$
\begin{aligned}
& U_{i}^{f}=U_{i}\left(\sum_{p=1}^{n} \sum_{n=1}^{m_{p}} F_{i\left(p n^{\prime}\right)^{x}}{ }_{\left(p n^{\prime}\right)^{\prime}} z_{p}\right. \\
& +\sum_{n=1}^{m_{i}} \sum_{p=1}^{n} \sum_{n^{\prime}=1}^{m_{p}} F_{(i n)\left(p n^{\prime}\right)} z_{(i n)\left(p n^{\prime}\right)} z_{i p} \\
& +\sum_{n=1}^{m_{i}} \sum_{p=1}^{n} F_{(i n) p} x_{i n} z_{i p} \\
& +\sum_{n=1}^{m_{i}} \sum_{p=1}^{n} \sum_{n^{\prime}=1}^{m_{p}} F_{\left(p n^{\prime}\right)(i n)} z_{\left(p n^{\prime}\right)(i n)} z_{i p} \\
& \left.+\sum_{p=1}^{n} \sum_{n=1}^{m_{i}} F_{p(i n)} x_{i n} z_{p i}+\sum_{p=1}^{i} \sum_{n^{\prime}=1}^{m_{p}} F_{\left(p n^{\prime}\right) i} x_{\left(p n^{\prime}\right)} z_{p i}\right) \\
& i=1,2, \ldots, n \text {. } \\
& S_{(i n)(j n)}^{f}=D^{f}\left[d_{(i n o)(j n} d_{)} \div\left(v^{f} \times 24\right)\right] \\
& i=1,2, \ldots, n, n^{o}=1,2, \ldots, m_{i}, \\
& n^{d}=1,2, \ldots, m_{i}, n^{o}<n^{d} .
\end{aligned}
$$

frequency of a feeder vessel within one-year planning horizon in the model (7) is given by:

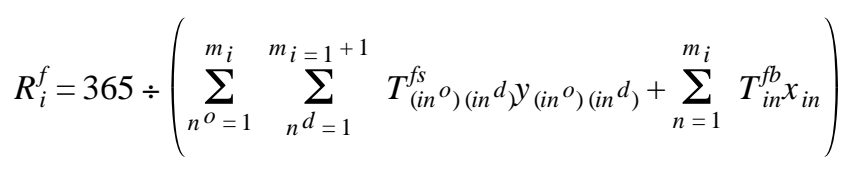

where $d_{\left(i n^{o}\right)\left(j^{d} d\right)}$ is the sailing distance between feeder port $i n^{o}$ and feeder port $i n^{d}, v^{f}$ represents the average sailing speed of a feeder vessel, $T_{(i n}^{f s}{ }^{o}\left({ }_{j n}{ }^{d}\right)$ is the sailing time of a feeder vessel on voyage leg $\left(i n^{o}, i n^{d}\right)$, and $T_{i n}^{f b}$ is the berthing time of a feeder vessel at feeder port in.

\section{SOLUTION METHODS}

As a result of the computational need for solving HLPs, past studies primarily focused on heuristic algorithms rather than exact solutions for models. O'Kelly (1987) expressed that the HLPs algorithm is NP-hard, which means the lack of a simple rule for solving the assignment of spokes to hubs. It is extremely difficult to obtain an exact solution to this NPhard problem using the enumeration method (Parker and Rardin 1982a, 1982b). In previous literature, there were two main approaches in dealing with the discrete optimization solution for HLPs (Bryan and O'Kelly, 1999). One was a heuristic, or non-exact, rule (O'Kelly, 1987; Aykin, 1990, 1994, 1995; Klincewicz, 1991, 1992, 1996; Skorin-Kapov and Skorin-Kapov, 1994; SkorinKapov et al., 1996; Campbell, 1996; Ernst and 
Krishnamoorthy, 1996, 1998) used to obtain the upper or lower boundary in order to ascertain a solution for the objective function. The other was to employ a linearization method, (Campbell, 1994; Skorin-Kapov et al., 1996; Sohn and Park, 1998; Hsieh and Chang, 2001) making the original model simple and easily calculable. Yet there are at least three shortcomings to using a linear programming model to solve HLPs. First, the solution to the number of hubs may not be an integer, and so does not meet the research requirements. Second, it increases the number of variables in the model, and is not appropriate for a large-scale network. Third, it is not suitable for the model's algorithms because it must fix the hub location at the beginning of each iteration.

In practice, hub ports are usually fixed for some time because of long-term contract, the limited hub candidates, and transfer cost of a hub (Sohn and Park, 1998). In this situation, the decision of optimal hub locations is important for economic consideration. But, the problem received limited attention in the literature. Most previous studies on HLPs assume the number of hubs to be constant (no more than four hubs); therefore, these models are unable to provide for the purposes of locating hubs. This paper applies a heuristic algorithm to simplify simple assignment of spokes to hubs. The concept, based on the shortest distance rule, allows each feeder port is assigned to its nearest hub port. Such an approach would possibly find an optimal solution to locate hubs, however, it still has computational complexity (e.g., for larger $n$-node problems there will be $C_{p}^{n}$ possible ways of locating $p$ sets of hubs). We only consider five sets of hubs $p$ (i.e., the number of hubs to be located) in our model for design, and then form a group with each one to further examine the spoke allocation model. In other words, the number of hub ports is given exogenously, whereas the model endogenously determines the location for hub ports.

In our earlier work, we indicated that there are three fundamental types of feeder route for spoke level: "shuttle," "direct," and "loop." Other variants can be derived from these basic types. This study adopts the assignment of "loop + direct" type as the basis for nonstrict hubbing policy since it reflects the reality of feeder routes and generates the maximum traffic flow (Hsieh and Wong, 2003). Hub ports are determined at the first stage, then the spoke allocation model tests all types of feeder routes based on single assignment with spokes to their nearest hubs chosen at first stage output.
When there is a new spoke allocation whose total profit is larger than that of a hub location model, then the allocation pattern with the largest total profit will be the best solution for that group. In this situation, a new spoke allocation is determined, but the "number" of hub ports remains the same. For each optimal set of the hubs chosen at the first stage, the spoke allocation model provides a basis to discern the best assignment of feeder route by the one with largest objective value. The solution procedure for the marine SNHLPs is shown in Figure 1.

\section{COMPUTATIONAL RESULTS}

This section summarizes the computational results obtained for the quadratic integer profit programming model with shortest-distance allocation schemes. The model was tested on a Trans-Pacific Routes with 12 major ports ${ }^{1}$. Estimates of online sources ${ }^{2}$ from certain harbor authorities are used because traffic flow data is not entirely available, and the transportation costs are

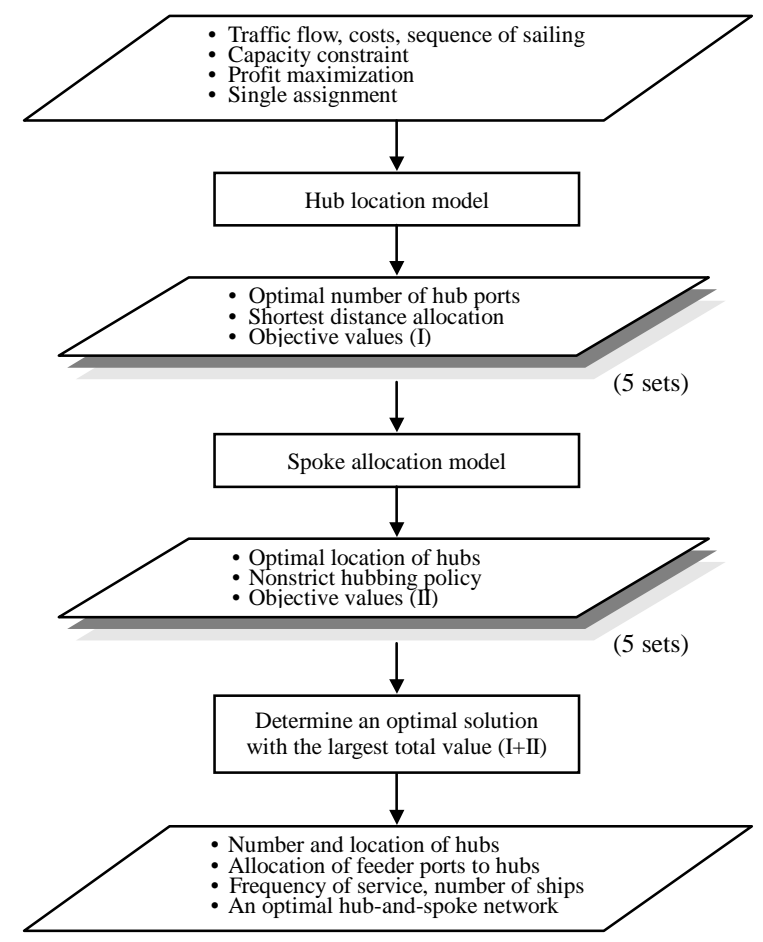

Fig. 1. The solution procedures of quadratic integer profit model for marine SNHLPs.

\footnotetext{
${ }^{1}$ Ports: 1. Singapore (SGSIN), 2. Manila (PHMNL), 3. Hong Kong (HKHKG), 4. Shanghai (CNSHA), 5. Kaoshiung (TWKHH), 6. Keelung (TWKEL), 7. Pusan (KRPUS), 8. Kobe (JPUKB), 9. Yokohama (JPYOK), 10. Tokyo (JPTYO), 11. Los Angeles (USLAX), 12. Long Beach (USLGB).

2 Sources: (1) Key Indicators 2003: Education for Global Participation, Asia Development Bank 2003, (2) Official U.S. Waterborne Transportation Statistics, Maritime Administration, Department of Transportation, 2003, (3) Containerization International Yearbook 2003, (4) Institute of Transportation, Ministry of Transportation and Communciations, Taiwan, R.O.C.
} 
provided by an international shipping company. This paper applies software Mathematica 4.0 to implement the solution algorithms.

In the first stage, for simplification, we deal with five networks with four to eight hub ports. Based on the shortest distance rule for single assignment, the five largest objective values in each group are selected for next phase of calculation. For example, consider a fourhub network, the five largest values in this group are: \{59.6850, 53.7269, 43.2166, 41.3481, 41.3005\}. Each value of them represents a network with different hub locations, respectively. These networks listed in descending order are: $\{3,4,11,12\},\{3,4,7,11\},\{3,4,5$, $11\},\{3,4,6,11\},\{3,4,10,11\}$. The rest of other networks with five to eight hub ports can be examined in the same way. The largest objective value in each group by hub location model is shown in Table 1 .

In the second stage, the model examines location of hubs and allocation of feeder ports to hubs. Those ports in each network that are not selected as hubs will be assigned to hubs nearest to them to form feeder networks, i.e., the spoke level. For example, the fourhub network with hubs $\{3,4,7,11\}$ has a single assignment pattern of $\{(1,3),(2,4),(5,4),(6,7),(8,7),(9,7)$, $(10,7),(11,7)\}$. Based on loop route type, this stage obtains the objective values for feeder network determined in the first stage. The five largest values for hourhub network are: $\{34.8803,20.6635,16.5496,15.6017$, $4.8501\}$. That means the network with five hubs listed in descending order are: $\{3,4,6,11\},\{2,3,4,11\},\{3$, $4,7,11\},\{3,4,11,12\},\{3,4,5,1\}$. The rest of other networks with five to eight hub ports can be obtained in the same way. The largest objective value in each group by spoke allocation model is shown in Table 2 .

Table 3 indicates that the five-hub network generates the largest objective value, followed by the sixhub, seven-hub, eight-hub, and four-hub network in descending order. That means the model endogenously

Table 1. The best solution in each group by hub location model for Trans-Pacific Routes

\begin{tabular}{cccl}
\hline $\begin{array}{c}\text { Objective } \\
\text { Value }\left(10^{6}\right)\end{array}$ & $\begin{array}{c}\text { Number } \\
\text { of Hubs }\end{array}$ & $\begin{array}{c}\text { Frequency of } \\
\text { Mother Vessels }\end{array}$ & \multicolumn{1}{c}{ Locations of Hubs } \\
\hline 59.6850 & 4 & 11.7 & HKHKG, TWKHH, USLAX, USLGB \\
69.6204 & 5 & 10.8 & HKHKG, TWKHH, KRPU, USLAX, USLGB \\
70.8051 & 6 & 10.5 & HKHKG, TWKHH, TWKEL, KRPU, USLAX, USLGB \\
70.6257 & 7 & 9.7 & PHMNL, HKHKG, TWKHH, TWKEL, KRPU, USLAX, USLGB \\
68.5595 & 8 & 9.0 & PHMNL, HKHKG, TWKHH, TWKEL, CNSHA, KRPU, USLAX, USLGB \\
\hline
\end{tabular}

Table 2. The best solution in each group by spoke allocation model for Trans-Pacific Routes

\begin{tabular}{cccl}
\hline $\begin{array}{c}\text { Objective } \\
\text { Value }\left(10^{6}\right)\end{array}$ & $\begin{array}{c}\text { Number } \\
\text { of Hubs }\end{array}$ & $\begin{array}{c}\text { Frequency of } \\
\text { Feeder Vessels }\end{array}$ & Locations of Hubs \\
\hline 34.8803 & 4 & 6 & HKHKG, TWKHH, CNSHA, USLAX \\
35.8838 & 5 & 5 & HKHKG, TWKHH, CNSHA, USLAX, USLGB \\
14.0180 & 6 & 3 & HKHKG, TWKHH, CNSHA, KRPU, USLAX, USLGB \\
11.1096 & 7 & 3 & HKHKG, TWKHH, CNSHA, KRPU, USLAX, USLAX, USLGB \\
7.7633 & 8 & 2 & PHMNL, HKHKG, TWKHH, CNSHA, KRPU, USLAX, USLAX, USLGB \\
\hline
\end{tabular}

Table 3. The best five solutions by quadratic integer model for Trans-Pacific Routes

\begin{tabular}{cccccl}
\hline Rank & $\begin{array}{c}\text { Total } \\
\text { Objective } \\
\text { Value }\left(10^{6}\right)\end{array}$ & $\begin{array}{c}\text { Hub } \\
\text { Location } \\
\text { Model }\end{array}$ & $\begin{array}{c}\text { Spoke } \\
\text { Allocation } \\
\text { Model }\end{array}$ & $\begin{array}{c}\text { Number } \\
\text { of Hubs }\end{array}$ & \multicolumn{1}{c}{ Locations of Hubs } \\
\hline 1 & 91.8068 & 55.9320 & 35.8838 & 5 & HKHKG, CNSHA, TWKEL, USLAX, USLGB \\
2 & 82.3502 & 68.3316 & 14.0186 & 6 & HKHKG, CNSHA, TWKEL, KRPUS, USLAX, USLGB \\
3 & 79.3634 & 68.2538 & 11.1096 & 7 & HKHKG, CNSHA, TWKHH, TWKEL, KRPUS, USLAX, USLGB \\
4 & 76.3228 & 68.5595 & 7.7633 & 8 & PHMNL, HKHKG, CNSHA, TWKHH, TWKEL, KRPUS, USLAX, USLGB \\
5 & 75.2867 & 59.6850 & 15.6017 & 4 & HKHKG, CNSHA, USLAX, USLGB \\
\hline
\end{tabular}


determines the five ports $\{3,4,6,11,12\}$ as the optimal location of hubs. The optimal hub-and-spoke network for the study case of Trans-Pacific Routes is shown in Figure 3. Three findings in this process of calculation worth to be noted: (1) With same number of hub ports, the profit generated by mother vessels is greater than that of feeder vessels. The hubbing structure allows larger vessels to take advantage of scale economies, resulting in lower cost per container for mother vessels compared to feeder vessels. (2) With same number of hub ports, the location for hub ports, which generates the largest profit on hub level (e.g., $\{3,4,11,12\}$ ), may not produce the largest profit on spoke level (e.g., $\{3,4$, $6,11\}$ ) because different types of feeder route affect the traffic flow at a hub port. (3) As the number of hub ports increases, the frequency of mother vessels and the number of feeder vessels decrease. Also, when the number of hub ports increases, the sailing distance of mother vessels increases as well, meaning the reduction of the frequency of mother vessels. Furthermore, the number of feeder vessels also decreases due to the decrease of feeder ports.

The total objective value of the network is obtained by the sum of respective objective value in two stages. The significance of total objective value lies in the fact that it represents an optimal hub-and-spoke network for routing containerships, while determining the number and the location of hub port, an assignment of feeder ports to hubs, the frequency of service, and the number of vessels deployed. The findings from solution process are as follows: (1) The maximal total objective value is not the sum of the maximal objective value of respective models, but the maximal objective value of

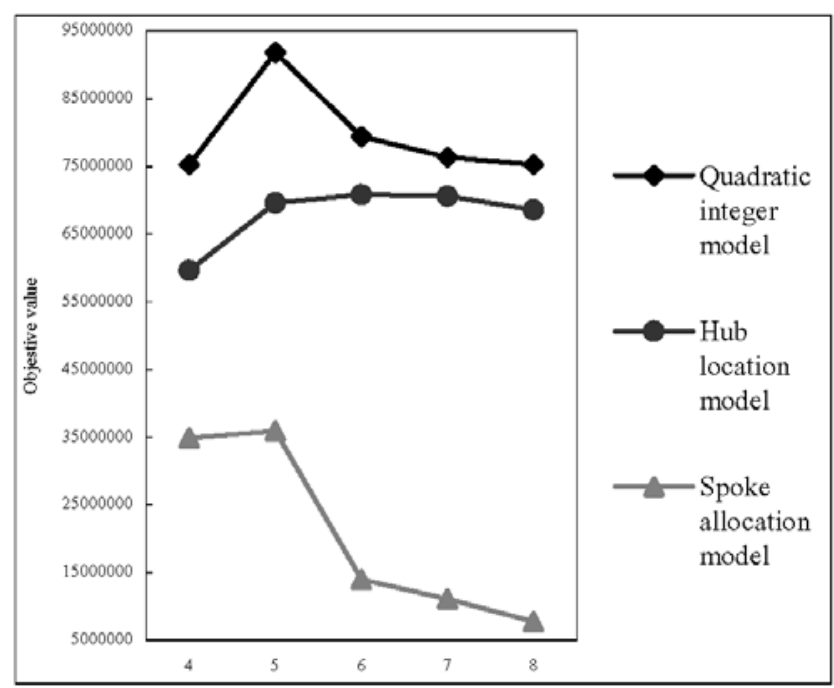

Fig. 2. The objective values by quadratic integer model with different number of hubs. the combined computation of the two models. This means that optimal allocations depend on the hub locations, and the optimal location of the hubs also depends on allocation decision. (2) The total objective value increases with the increase of the number of hub ports to the stationary point and then decreases as the number of the hub port further increases. This indicates that the model is a form of concave function and the economies of scale exist in the relationship between total profit and the number of hubs, as shown in Figure 2. (3) The total profit of the network lies in the selection of hub locations. This implies that the proper design for feeder routes would increase the total profit because spoke allocation model would change an optimal choice of hub locations. (4) The port cost and the loading cost of a port are factors in the selection of hub port. For example, CNSHA does not have much traffic flow, yet it is selected as a hub port due to its lower port cost and loading cost. (5) The ports with larger traffic flow are usually selected as hub ports in this model, (e.g., HKHKG, TWKHH, USLAX, and USLGB). It is able to interpret the economies of scale that result from hubbing.

\section{CONCLUSIONS}

In this paper we propose a new model to adequately capture the characteristics for routing containerships. The routing structure is far from a pure hub-and-spoke network. The problems involved with routing containerships are defined as SNHLPs. A quadratic integer programming model associated with additional constraints is formulated for solving the problems. The model consists of two-stage computational algorithms, a hub location model and a spoke allocation model. The location of hubs, the frequency of service, and the number of vessels included in the model are decision variables. Other aspects of the

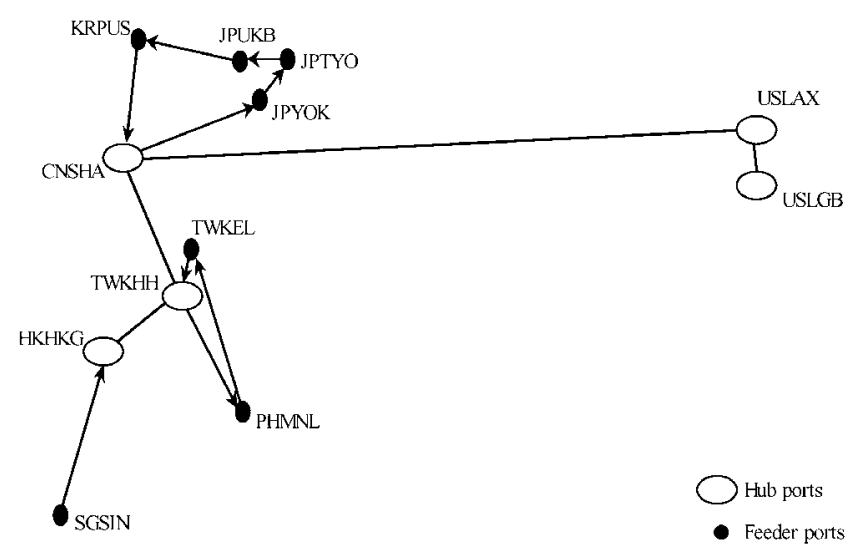

Fig. 3. An optimal hub-and-spoke network with the largest total profit for the data from Trans-Pacific Routes. 
problem are the objective function of profit maximization, the asymmetry of the demand matrix, and the loop type for feeder routes.

Employing the heuristic algorithms based on shortest distance to simply single assignment, it is possible to compute solutions to the model. It is tested on data sets from Trans-Pacific Routes to illustrate its formulation and solution algorithms. The results indicate that optimal allocation of spokes to hubs depends on hub locations, and optimal location of the hubs also depends on allocation decision. Another results demonstrate that the objective function of the model is a form of concave function, exploiting the economies of scale in the relationship between the total profit and the number of hubs.

Implementing hub-and-spoke networks benefits liner operators the scale economies from hubbing. This paper proposes mathematical models of hub systems in as effort to enhance understanding of marine SHNLPs. One advantage of the model studied in the paper could be considered for liner operators to relocate or add hubs to an existing network when choosing strategic ship routes. Also, the model could serve as a reminder of the impact of feeder routes on location of hubs for a network design.

A heuristic scheme allows us to find solutions to this problem. Yet this restriction for single assignment does not guarantee that it is the optimal way. Future researches may attempt using total enumeration method for an exact solution to marine problems (under 20 nodes). Moreover, future researches may modify the model by relaxing the assumption of the problem, such as multiple assignment and hub capacity. Finally, additional research needs to be conducted on sensitivity analysis of the model's behavior, especially the discount factor.

\section{ACKNOWLEDGEMENTS}

The authors are very grateful to the editor, Professor Chorng-Liang Pan, and two anonymous referees for their astute observations and helpful comments. This project was supported by the National Science Council of Taiwan with grant 90-2416-H-009-004.

\section{REFERENCES}

1. Aykin, T., "On a Quadratic Integer Program for the Location of Interacting Hub Facilities," Eur. J. Oper. Res., Vol. 46, pp. 409-411 (1990).

2. Aykin, T., "Lagrangean Relaxation Based Approaches to Capacitated Hub-and-Spoke Network Design Problem," Eur. J. Oper. Res., Vol. 79, pp. 501-523 (1994).

3. Aykin, T., "Networking Policies for Hub-and-Spoke
Systems with Applications to the Air Transportation System," Transp. Sci.,Vol. 29, pp. 201-221 (1995).

4. Azaron, A. and Kianfar, F., "Dynamic Shortest Path in Stochastic Dynamic Network: Ship Routing Problem," Eur. J. Oper. Res., Vol. 144, pp. 138-156 (2003).

5. Boland, N., Krishnamoorthy, M., Ernst, A.T., and Ebery, J., "Preprocessing and Cutting for Multiple Allocation Hub Location Problems," Eur. J. Oper. Res., Vol. 155, pp. 638-653 (2004).

6. Bryan, D.L. and O'Kelly, M.E., "Hub-and-Spoke Network in Air Transportation: An Analytical Review," $J$. Reg. Sci., Vol. 39, No. 2, pp. 275-295 (1999).

7. Campbell, J.F., "Integer Programming Formulations of Discrete Hub Location Problems," Eur. J. Oper. Res., Vol. 72, pp. 387-405 (1994).

8. Campbell, J.F., "Hub Location Problems and the p-Hub Median Problem," Oper. Res., Vol. 44, pp. 923-935 (1996).

9. Chadwin, M.L., Pope, J.A., and Talley, W.K., Ocean Container Transportation: An Operational Perspective, Taylor and Francis, Inc., New York (1990).

10. Cho, S.C. and Perakis, A.N., "Optimal Liner Fleet Routing Strategies," Marit. Policy Manage., Vol. 23, No. 3, pp. 249-259 (1996).

11. Christiansen, M. and Nygreen, B., "A Method for Solving Routing Problems with Inventory Constraints," Annals Oper. Res., Vol. 81, pp. 357-378 (1998).

12. Chu, C.W., Kuo, T.C., and Shieh, J.C., "A Mixed Integer Programming Model for Routing Containerships," $J$. Mar. Sci. Technol., Vol. 11, No. 2, pp. 96-103 (2003).

13. Ebery, J., Krishnamoorthy, M., Ernst, A.T., and Boland, N., "The Capacitated Multiple Allocation Hub Location Problem: Formulations and Algorithms," Eur. J. Oper. Res., Vol. 120, pp. 614-631 (2000).

14. Ernst, A.T. and Krishnamoorthy, M., "Efficient Algorithms for the Uncapacitated Single Allocation $p$-Hub Median Problem," Locat. Sci., Vol. 4, pp. 139-154 (1996).

15. Ernst, A.T. and Krishnamoorthy, M., "Exact and Heuristic Algorithms for the Uncapacitated Multiple Allocation p-Hub Median Problem," Eur. J. Oper. Res., Vol. 104, pp. 100-112 (1998).

16. Fagerholt, K., "Optimal Fleet Design in a Ship Routing Problem," Int. Trans. Oper. Res., Vol. 6, pp. 453-464 (1999).

17. Gilman, S., Container Logistics and Terminal Design. International Bank for Reconstruction and Development, Washington, DC (1981).

18. Hsieh, S.H. and Chang, F.R., "Applications of the Huband-Spoke Network Model in Routing Liner Ships," Transp. Plan. J., Vol. 30, No. 4, pp. 871-890 (2001).

19. Hsieh, S.H., Sung, W.C., and Wong, H.L., "A Profit Maximization Model for Routing Containerships," Paper Presented at the Proceedings of the Serventeen 
Annual Conference for the Chinese Institute of Transportation, Taiwan (2002).

20. Hsieh, S.H. and Wong, S.L., "A Marine Hub-and-Spoke Network Model Allowing the Feeder Ports Not to Directly Connect to Hub Ports," The Transportation Research Board Annual 82 $2^{\text {nd }}$ Meeting, National Research Council, Washington, DC (2003).

21. Jaramillo, D.I. and Perakis, A.N., “Fleet Deployment Optimization for Liner Shipping. Part 1: Background, Problem Formulation and Solution Approaches," Marit. Pollog. Manage., Vol. 18, pp. 183-200 (1991).

22. Kara, B.Y. and Tansel, B.C., "On the Single-Assignment p-Hub Center Problem,” Eur. J. Oper. Res., Vol. 125, pp. 648-655 (2000).

23. Kara, B.Y. and Tansel, B.C., "The Single-Assignment Hub Covering Problem: Models and Linearizations," $J$. Oper. Res. Soc., Vol. 54, pp. 59-64 (2003).

24. Klincewicz, J.G., "Heuristics for the p-Hub Location Problem,” Eur. J. Oper. Res., Vol. 53, pp. 25-37 (1991).

25. Klincewicz, J.G., "Avoiding Local Optima in the $p$-Hub Location Problem Using Tabu Search and Grasp," Annals Oper. Res., Vol. 40, pp. 283-302 (1992).

26. Klincewicz, J.G., "A Dual Algorithm for the Uncapacitated Hub Location Problem," Locat. Sci., Vol. 4, pp. 173-184 (1996).

27. Lu, H.A., "Modelling Ship's Routing Bounded by the Cycle Time for Marine Liner," J. Mar. Sci. Technol., Vol. 10, No. 1, pp. 61-67 (2002).

28. Mourao, M.C., Pato, M.V., and Paixao, A.C., "Ship Assignment with Hub-and-Spoke Constraints," Marit. Policy Manage., Vol. 29, No. 2, pp. 135-150 (2002).

29. O'Kelly, M.E., “The Location of Interacting Hub Facilities," Transp. Sci., Vol. 20, No. 2, pp. 92-106 (1986a).

30. O’Kelly, M.E., "Activity Levels at Hub Facilities in Interacting Networks," Geogr. Anal., Vol. 18, pp. 343356 (1986b).

31. O’Kelly, M.E., “A Quadratic Integer Program for the Location of Interacting Hub Facilities," Eur. J. Oper. Res., Vol. 32, pp. 393-404 (1987).

32. O'Kelly, M.E. and Lao, Y., "Mode Choice in A Huband-Spoke Network: A Zero-One Liner Programming Approach," Geogr. Anal., Vol. 23, pp. 283-297 (1991).

33. O'Kelly, M.E., "Hub Facility Location with Fixed Costs," J. Reg. Sci., Vol. 71, No. 3, pp. 293-306 (1992).

34. O'Kelly, M.E., Skorin-Kapov, D., and Skorin-Kapov J., "Lower Bounds for the Hub Location Problem," Manage.
Sci., Vol. 41, No. 4, pp. 713-721 (1995).

35. O'Kelly, M.E., Bryan, D.L., Skorin-Kapov, D., and Skorin-Kapov J., "Hub Network Design with Single and Multiple Allocations: A Computational Study," Locat. Sci., Vol. 4, No. 3, pp. 125-138 (1996).

36. O'Kelly, M.E., “A Geographer's Analysis of Hub-andSpoke Networks," J. Transp. Geogr., Vol. 6, No. 3, pp. 171-186 (1998).

37. O'Kelly, M.E. and Miller, H.J., "The Hub Network Design Problem: a Review and Synthesis," J. Transp. Geogr., Vol. 2, No. 1, pp. 31-40 (1994).

38. Pamuk, F.S. and Sepil, C., "A Solution to the Hub Center Problem via A Single-Relocation Algorithm with Tabu Search,” IIE Trans., Vol. 33, pp. 399-411 (2001).

39. Parker, R.G. and Rardin, R.L., "An Overview of Complexity Theory in Discrete Optimizations: Part I. Concepts," IIE Trans., Vol. 14, No. 1, pp. 3-10 (1982a).

40. Parker, R.G. and Rardin, R.L., "An Overview of Complexity Theory in Discrete Optimizations: Part II. Results and Implications," IIE Trans., Vol. 14, No. 2, pp. 83- 89 (1982b).

41. Pearson, R. and Fossey, J., World Deep-Sea Container Shipping, Gower Publishing Co., Aldershot, England (1983).

42. Powell, B.J. and Perakis, A.N., "Fleet Deployment Optimization for Liner Shipping: An Integer Programming Model," Marit. Policy Manage., Vol. 24, No. 2, pp. 183192 (1997).

43. Rana, K. and Vickson, R.G., "A Model and Solution Algorithm for Optimal Routing of a Time-Charted Containership," Transp. Sci., Vol. 22, pp. 83-95 (1988).

44. Rana, K. and Vickson, R.G., "Routing Containerships Using Lagrangian Relaxation and Decomposition," Transp. Sci., Vol. 25, pp. 201-214 (1991).

45. Ronen, D., "Ship Scheduling: The Last Decade," Eur. J. Oper. Res., Vol. 71, pp. 325-333 (1993).

46. Skorin-Kapov, D. and Skorin-Kapov, J., "On Tabu Search for the Location of Interacting Hub Facilities," Eur. J. Oper. Res., Vol. 73, pp. 502-509 (1994).

47. Skorin-Kapov, D., Skorin-Kapov, J., and O'Kelly, M.E., "Tight Liner Programming Relaxations of Uncapacitated p-Hub Median Problems," Eur. J. Oper. Res., Vol. 94, pp. 582-593 (1996).

48. Sohn, J. and Park, S., "Efficient Solution Procedure and Reduced Size Formulations for $p$-Hub Location Problems," Eur. J. Oper. Res., Vol. 108, pp. 118-126 (1998). 